\title{
On the performance of a polycrystalline PV panel under different impulse voltages and temperatures
}

\begin{abstract}
Lightning events are one of the factors that affect performance of a solar power system either by direct or indirect strikes. When lightning strikes directly to a panel, it can affect function and life cycle of the panel. Therefore, considering the electrical performance characteristics such as open-circuit voltage, short-circuit current, and maximum power of the solar panels under high voltage conditions is an important issue. In this paper, the effect of impulse voltage on the change of electrical behaviour of a polycrystalline solar panel is studied. The experimental platform is tested by a lightning impulse generated over a range of $100 \mathrm{kV}$ to $300 \mathrm{kV}$. The results revealed that as the lightning impulse voltage is increased, the maximum power output gradually decreases. The performance of percentage difference from normal between $100 \mathrm{kV}$ to $300 \mathrm{kV}$ increased to $10.02 \%$ for the maximum power output and the graph showed an increasing non-linear trend. After testing with lightning impulse voltages, the electrical performance of the solar panel under different thermal conditions (temperature) was evaluated in the range of $25^{\circ} \mathrm{C}$ to $70{ }^{\circ} \mathrm{C}$ and the results are discussed accordingly. When the different temperatures were applied, efficiency of the polycrystalline panel continuously degraded. The percentage difference of the maximum power between samples of $100 \mathrm{kV}$ to $300 \mathrm{kV}$ at $70{ }^{\circ} \mathrm{C}$ increased from $2.09 \%$ to $7.11 \%$.
\end{abstract}

Keyword: Lightning impulse voltage; Photovoltaic (PV); Polycrystalline; Temperature; Thermal 